\title{
La cristiandad cuestionada: intelectuales católicos en Argentina (1950-1965)
}

\author{
Christendom Challenged: Catholic intellectuals in Argentina (1950-1965)
}

\author{
José A. Zanca \\ Doctor en História \\ Profesor da Universidad de San Andrés/CONICET \\ jzanca@udesa.edu.ar
}

Resumen: Desde el atardecer del papado de Pío XII a la finalización del Concilio Vaticano II, el catolicismo vivió una autentica revolución interna. El trabajo propone analizar la trayectoria de los discursos de la intelectualidad católica argentina en las décadas del cincuenta y sesenta, y las condiciones que hicieron posible ese cambio. El período conciliar fue capaz de modificar el sistema de relaciones al interior del catolicismo y las formas de sanción y legitimidad de los discursos en el campo: lo decible y no decible sufrió una transformación radical. Temas como el rol de los laicos, el pluralismo, el diálogo ecuménico, la relación Iglesia - Estado, etc., formaron las coordenadas de ese intenso debate.

Palavras-chave: Intelectuales católicos, Iglesia argentina, Concilio Vaticano II, Pío XII, Historia de la Iglesia.

\begin{abstract}
From the decline of Pius XII's papacy to the end of the Vatican Council II, Catholicism faced an actual internal revolution. This paper seeks to analyse the development of discourse in Argentinian catholic thinkers in the 1950s and 1960s; and the conditions under which this change has been possible. The conciliary period was capable of transforming the inner relational system in catholicism and modifying the ways of sanction and legitimacy of discourse in the field: what can and what cannot be said underwent a radical transformation. Issues such as the role of laymen, pluralism, ecumenical dialogue, the relationship Church-State, etc., set up the coordinates of this intense debate.
\end{abstract}

Key words: catholics thinkers, Argentinian Church, Vatican Council II, Pius XII, Church History. 
El presente ensayo intenta dar cuenta, en forma sintética, de las principales transformaciones operadas en la cultura católica en las décadas del cincuenta y sesenta. Por un lado es posible apreciar el surgimiento de una generación de intelectuales, que vio la luz pública después de 1955, adscribió al programa del humanismo cristiano y fue portadora de una mirada distinta a la de sus predecesores nacionalistas e integristas de la década del treinta y cuarenta. Por otro lado, las relaciones de autoridad dentro del campo se trastocaron por el surgimiento de una esfera crítica dentro del catolicismo, que obtuvo carta de ciudadanía con el Concilio Vaticano II. El trabajo se inicia con la emisión de la encíclica Humani Generis en 1950, en la que Pío XII advertía sobre las desviaciones del pensamiento católico, y se cierra con la aprobación de la constitución pastoral sobre la Iglesia y el mundo moderno Gaudium et Spes, en la clausura del Concilio Vaticano II, que hizo propias muchas de la ideas condenadas quince años antes.

\section{La generación del cincuenta}

Desde el derrocamiento del peronismo en 1955, los intelectuales católicos fueron acusados por sus pares no confesiones de complicidad con el régimen depuesto. Sin embargo, el catolicismo hacía tiempo que había dejado de ser un campo homogéneo. En torno a la Guerra Civil española (1936-1939) se produjo una disputa que partió las aguas entre quienes apoyaban a Franco y quienes recelaban de una alianza entre católicos y fascismo. Durante la Segunda Guerra mundial esa diferencia se agudizó, al punto que los católicos antifascistas contaron con sus propias revistas y se sumaron a organizaciones como Acción Argentina y la Junta de la Victoria, destinadas a apoyar la causa aliada. Se fue dibujando así el perfil de un católicismo progresista. Con la llegada del peronismo en 1946, la jerarquía eclesiástica se mostró como una aliada del poder. Esto sirvió para que los grupos de izquierda anticlerical refrendaran sus teorías sobre la connivencia entre sectores totalitarios y reaccionarios. Sin embargo, a partir de 1954 los católicos, junto a radicales, militares y la izquierda liberal se unieron y apoyaron el derrocamiento de Perón. Esa unidad duraría poco. A partir de 1956, se abrió un conflicto a proposito del decreto de reordenamiento universitario involucró en forma polémica a los intelectuales católicos y al resto del universo cultural argentino (de raíces profundamente laicistas), demostrando que la convivencia había sido un producto circunstancial del enfrentamiento con el 
peronismo. ${ }^{1}$ Luego de una corta primavera durante el año '55, los católicos y el resto de los intelectuales volvieron a distanciarse.

Pero tal vez esta situación no fuera la excepción sino la regla. Los intelectuales católicos habían sido protagonistas de la escena pública en las décadas del '30 y del '40, vaciando en el molde del nacionalismo la frustración que arrastraban desde mediados del siglo XIX. Luego de dos décadas en las que concentraron parte de la atención pública, en 1955 estaban de nuevo en el punto de partida. Solos, enajenados de una cultura nacional cada vez más laica, más anticlerical y politizada, parecían atados a su pasado. Aunque no podían desconocer esa realidad, en algún punto parecía no importarles. Los más belicosos buscaban en el otro los defectos de tal estado de cosas. Según Mauricio Pérez Catán, los intelectuales argentinos criticaban a los católicos porque en definitiva eran "sectarios, y como tales, más o menos totalitarios, que aspiran a hacer un 'peronismo al revés', como lo han demostrado con su demagogia e inquisición, no siempre bien disimulada" (PÉREZ CATÁN, 1956: 25).

Gustavo Martínez Zuviría lamentaba que, después de 1958, la marginación de los intelectuales católicos se hubiese convertido en indiferencia:

Dice el señor 'si el mundo os aborrece, sabed que primero me aborreció a mí [...] y el pobre intelectual contesta: Si señor. Pero lo malo es que nadie me persigue ¡Ojalá me persiguieran! Porque harían ruido a mi alrededor y me harían conocer. El silencio es la mayor arma de nuestros enemigos, que son los vuestros Señor (WAST, 1958: 763).

Asumir ese lugar marginal no siempre implicó la construcción de puentes para reencontrarse con el mundo moderno. La cristiandad era el ideal que defendían los católicos integralistas. Las asociaciones católicas construídas desde principio de siglo eran espacios en los que los laicos podían estar protegidos del contacto con el pecado. Si bien nunca llegaron a parecerse a los pilares belgas, se trataba de organizaciones que encuadraban a los sujetos desde la infancia hasta la adultez. En particular los intelectuales se movían en un circuito propio de publicaciones (como las revistas Criterio, Estudios o

\footnotetext{
${ }^{1}$ A fines de 1955, el ministro de educación de la Revolución Libertadora e intelectual católico, Atilio Dell'Oro Maini, elaboró un decreto que reorganizaba el sistema universitario. Por un lado, restituía la autonomía a las universidades públicas, siguiendo los preceptos de la Reforma de 1918. Pero por el otro, habilitaba la creación de universidades privadas, con capacidad de emitir títulos habilitantes. Esto produjo un enfrentamiento que se prolongó por los siguientes años, y que tuvo picos de tensión durante el gobierno democrático posterior, de Arturo Frondizi, que terminó convalidando el proyecto de Dell'Oro.
} 
el diario El Pueblo), editoriales, e instituciones culturales. Se trataba de un sueño de perfección y pureza que les daba a los católicos un conjunto de seguridades, refrendadas en ámbitos de sociabilidad que cimentaban un verdadero sistema de obligaciones compartidas. ¿Qué había 'afuera', que realmente valiera la pena? Martínez Zuviría exorcizaba cualquier intento de borrar las fronteras entre uno y otro mundo. "Los católicos" denunciaba "aceptan muchas veces con demasiada generosidad, las famas y las obras del campo contrario". De esa complacencia con la modernidad, de ese conformismo con el mundo "anticatólico", nacía el relajamiento que le hacía temer a Zuviría que al joven intelectual católico "a al corta o a la larga pueden nacerle tentaciones de cambiar, de pasarse a la otra trinchera" (WAST, 1958: 766).

Pero esos jóvenes ya existían. Habían formado una nueva conciencia bajo la universidad opresiva del peronismo, preguntándose si ésa era la revolución nacional que predicaban sus mayores. Leyeron a los clásicos del catolicismo de los años '30; conocieron a Maritain, a Bloy, a Berdiaeff y a Chesterton, pero también a los "sospechosos": Folliet, Guitton, Teilhard de Chardin, y Mounier. Tomaron contacto con ellos en grupos de estudio reducidos, de la mano de religiosos carismáticos como Moledo, Franceschi, Etcheverry Boneo y también Meinvielle. Conocieron a los escritores católicos de la postguerra europea, y se enamoraron de la imagen de un catolicismo más íntimo y menos belicoso, más terrenal y menos triunfante. Esa nueva generación, que algunos llamaron "del cincuenta", no conoció la seguridad de sus mayores. Los católicos de la entreguerra habían gozado de un conjunto de convicciones sobre las que se erigieron como cruzados. Sabían que este mundo era irreconciliable con su imagen de Cristo y no admitieron transacciones, desplazándose en un medio fragmentado por ideas absolutas y opuestas. Los jóvenes del cincuenta también crecieron en una sociedad dividida, pero con el peronismo, el clima de la postguerra y las vísperas del Concilio, su pesimismo se trastocó en confianza, y creyeron poder establecer un diálogo con la modernidad. Adoptaron como programa el humanismo cristiano, una síntesis de sus aspiraciones de renovación. Si bien no se trataba de una ideología cerrada, estaba encuadrada por una serie de coordenadas. Se trataba, en principio, de una mirada crítica de la relación entre la iglesia y el mundo moderno. Desde que en 1936 Maritain escribió Humanismo integral, el destacado tomista francés decretó que la cristiandad estaba muerta, y que era necesario adecuar la práctica religiosa a una sociedad profana (MARITAIN, 1936). Su programa reivindicaba la tolerancia religiosa, la revalorización del rol del laicado, la apertura de un espacio para la participación y el debate, la puesta en duda de cuestiones que formaban 
parte de la tradición de la Iglesia. Algunos de los representantes de esta fluida corriente en Arentina fueron Carlos Floria, Ludovico Ivanissevich Machado, José Luis de Imaz, Jorge Mejía, Natalio Botana, Guido Di Tella, Antonio Donini, Rafael Braun, Justino O'Farrel, Alberto Sily, José E. Miguens - por sólo nombrar a algunos -, que poblaron las páginas de revistas de larga tradición en el catolicismo argentino como Criterio y Estudios. Para Martínez Zuviría, sólo "deleitaban al enemigo, que tiene singular predilección por los católicos 'discretos'" (WAST, 1958:765).

Esos jóvenes rechazaron la intrasigencia de la generación que los precedió. Les interesaba la política tanto como la fe, pero las consideraron esferas autónomas. Dudaron de que la rigidez moral de la Iglesia fuera el único valor que la religión pudiera brindarle a la sociedad. Las ciencias sociales sirvieron de vehículo para su cambio de perspectiva. Los intelectuales católicos de los treinta y cuarenta fueron en su mayoría religiosos, filósofos y abogados. Los jóvenes del cincuenta se convirtieron en sociólogos, cientistas políticos, economistas e historiadores, y les tocó participar en la modernización de cada una de sus disciplinas. Tomaron distancia de sus propias convicciones y pudieron auto interpretarse desde una perspectiva diferente a la de sus mayores. Obtuvieron becas y viajaron. Algunos conocieron universidades católicas europeas, que desde la postguerra hablaban un nuevo lenguaje. Practicamente todos los mencionados en el párrafo anterior hicieron estancias de investigación, viajes iniciaticos u obtuvieron títulos de posgrado durante las décadas de 1950 y 1960. ${ }^{2}$ Algunos, como José Enrique Miguens, en los años de 1940.

Pero la nueva generación no cometió un parricidio. Las obligaciones sociales eran una atadura muy fuerte dentro del catolicismo. Los jóvenes del cincuenta simplemente dejaron atrás a la generación que les precedió, sin sistematizar una crítica que sirviera para una ruptura formal. La transición se suavizó por la existencia de intelectuales como Gustavo Franceschi, que compartían ideas de los dos mundos. Había nacido en París, en 1881. Siendo un niño llegó a Buenos Aires, cursó sus estudios en el Seminario Metropolitano y fue ordenado sacerdote en 1904. Desde temprano se destacó tanto por su participación en diversas iniciativas sociales del catolicismo, como en su rol de intelectual confesional. Su figura y sus ideas -que imprimió como director de la revista Criterio desde 1932 hasta 1957- resumen muchas de las tensiones en las que se definía el rol del

\footnotetext{
${ }^{2}$ Carlos Floria y José Luis de Imaz fueron ganadores de la beca Eisenhower y se vincularon al mundo académico norteamericano. Mucho antes, José E. Miguens había cursado estudios de posgrado en Harvard. Natalio Botana y Rafael Braun estudiaron en la universidad católica de Lovaina.
} 
intelectual católico en la primera mitad del siglo XX. Su muerte en 1957 lo libró de un tiempo de enfrentamientos en el seno de la Iglesia donde, obligado a definiciones, no hubiese podido mantener su tono conciliador. Su postura frente a la democracia había sido siempre ambigua, su recelo hacia el liberalismo era parte de la doctrina que había sostenido su pensamiento. ${ }^{3}$ Pero eso no le impedía criticar a quienes en los años treinta habían despreciado a las instituciones que garantizaban la libertad. Los escritos de sus últimos años, después de la caída del peronismo, se concentraron en aquellos temas que afectaban la conciencia común de los católicos, y que luego serían recogidos por el Concilio Vaticano II: la cuestión social, la relación con el mundo moderno, la reconciliación con otros cultos, o el distanciamiento del Estado.

Esta nueva generación de intelectuales católicos quedó en una posición ambigua. No rompió en forma explícita con la tradición del nacionalismo católico que lo precedió, aunque sus ideas y su programa eran claramente diferentes. Por otro lado, tampoco se reconcilió con el resto del mundo cultural. El conflicto universitario de esos años por la autorización al funcionamiento de casas de altos estudios privadas separó más y más las trincheras. Los católicos de la nueva generación quedaron atrapados entre la reivindicación de un pasado al que se sentían atados pero sin conformidad, y una nueva intelectualidad de izquierda que les exigían renuncias y rupturas que, por la conformación propia del campo y su relación con la jerarquía eclesiástica, ellos no podían aceptar.

En otras condiciones, el paralelo cultural de estos jóvenes hubiera sido la generación de Contorno. ${ }^{4}$ Sin embargo, no existió un verdadero diálogo entre ambas. A los católicos les agradaba la reivindicación que hacían los contornistas de figuras como Arlt, Quiroga o Cambaceres, tal vez por un desprecio común hacia el liberalismo de las

\footnotetext{
${ }^{3}$ Beatriz Sarlo describió la duda que enfrentaba el catolicismo social “¿Cuáles son las grandes líneas de organización de una democracia que evite los límites que a la justicia social pone el liberalismo, con su despliegue conflictivo de los intereses individuales, y el totalitarismo, con su intervención incontrolable tanto en la esfera privada como su absorción por el estado en los órganos de la comunidad?" (Sarlo, 2001: 47). El pensamiento de Franceschi vivió en ese dilema hasta sus últimos días. Una editorial de 1957 todavía defendía el régimen autoritario de Oliveira Salazar en Portugal por sus éxitos económicos "Es el modelo de austeridad personal y de la austeridad gubernativa. No ha pretendido conquistar al pueblo con discursos sino con hechos, no ha hablado de derechos sino de deberes, ha mostrado que únicamente el camino de la privación era el que permitiría reconstruir el mañana haciéndolo digno del pasado" (FRANCESCHI, 1957: 213).

${ }^{4}$ En un artículo de 1958, Hector Ferreiros señalaba en referencia al grupo Contorno "...sus tópicos son anti-imperialistas, de lucha de clases, laicistas... en fin, un esquema marxista pero nacional y que últimamente cumpliendo con la predicción de José Chiaramonte: 'si no se inclinan a un socialismo científico...llegaran al borde de eso que es el saldo negativo de la Reforma, el aprismo...". En forma paralela a Contorno, Ferreiros ubicaba al grupo de católicos de la revista Ciudad, dirigida por Carlos Manuel Muñiz, e integrada por Ezequiel Lezama, Ludovico Ivanissevich Machado, Eduardo Dessein, Magdalena Harriague, Eugenio Guasta y Rafael Squirru entre otros (FERREIROS, 1958: 250).
} 
letras argentinas. Sin embargo, el existencialismo y el izquierdismo anticlerical del grupo marcaron una frontera infranqueable. "Un Dios cotidiano" de Viñas, donde se relataban episodios de la vida de un sacerdote en la Argentina de fines de los treinta, fue rechazado con vehemencia por los críticos de Estudios y Criterio. Le reprocharon a Viñas "hablar de lo que no siente", y Gustavo Ferrari de Criterio sostuvo que el autor fracasó porque "el tema se le resbala de las manos, nunca está del todo a su alcance" (FERRARI, 1958: 250). Héctor Ferreiros, de Estudios, disparó contra el libro y sostuvo que en él "muchas ideas no abundan" (FERREIROS, 1958: 251). Sin embargo, y a pesar de la dureza de las críticas, no había en los argumentos un fundamento clerical contra la obra. Lo que rechazaban de "Un Dios cotidiano" era la caricaturización de los problemas que ellos enfrentaban a diario: la forma de experimentar la fe, la presencia de Cristo en sus vidas, la relación con el mundo moderno y con la jerarquía de la Iglesia. A fines de los cincuenta, los católicos querían dejar de ser la viñeta que el resto de los intelectuales hacía de ellos: un grupo cerrado e intolerante, tradicionalista y timorato. Los católicos estaban cambiando y querían que el mundo lo supiera. Aunque no buscaban agradar, como los acusaba Martínez Zuviría, creían que era posible reintegrarse en el campo intelectual, diferenciándose de la intolerancia de sus predecesores.

A pesar de ese corte incompleto, a través de sus palabras es fácil apreciar la búsqueda de un perfil propio. Los jóvenes del cincuenta crecieron de golpe y se consideraban con derecho a reclamar cambios en el estilo del catolicismo. "Es paradojal", sostenía Carlos Floria en 1958,

...que la necesidad de tener sentido común, tacto, ha sido más comprendida por los jóvenes de 35 años para abajo que por los más maduros. Creo que ello ocurre porque los cambios han sido tan febriles en estos 12 años que hemos recorrido uno 60 años de historia mundial [...] Los jóvenes nos hemos dado cuenta porque no temimos a la muerte, que más difícil que ser héroe es saber enfrentar con dignidad, sacrificio y entrega las muchas dificultades de todos los días (FLORIA, 1958: 812).

En 1955 Floria describió la posición de su generación a través de los hombres del '37. El lenguaje elusivo del pasado le servía para expresar su necesidad de pensar la realidad más allá de las antinomias del momento. Bajo el rosismo, que al igual que el peronismo había producido "una sociedad subvertida, desorientada, adormecida, 
moralmente vacilante y materialmente débil", surgió una generación desamparada que "se mantuvo por la fuerza equidistante de una política fragmentaria, improvisada que vivía al día, y de una oposición zigzagueante". El ejemplo de la generación del '37 era un programa de acción en sí mismo, basado en el desprecio al calor del poder y las seguridades; era un rechazo a las íntimas relaciones entre la jerarquía católica y el Estado de la última década, y al nacionalismo como una ideología que no dejaba resquicio para las dudas o el debate. La generación del '37, como la del cincuenta, era una frontera con las adyacencias, que no se fundía con ninguna de ellas y "ese es el drama que arrastra consigo". El Peronismo, a pesar de ser "una provocación antinatural, como es todo sistema que no respeta el valor original de la libertad humana", sirvió para que los católicos revalorizaran las instituciones democráticas. "La generación del 37 está sola" concluye Floria "su desamparo en medio de las fracciones en lucha no trajo desilusión, pero sí desconfianza" (FLORIA, 1955: 649-650).

La experiencia del año 55 rompió los moldes de la inocencia que todavía quedaban entre los católicos. Los jóvenes del cincuenta se enajenaron del mundo de la política y ese distanciamiento transformó su mirada. Estaban más convencidos de poder influir en la opinión pública y en la dirigencia católica, que en hermanarse en una ideología para participar en la lucha por el poder. Ese distanciamiento era producto de la mala relación con el mundo de los partidos y la intolerancia de los católicos hacia su actividad cotidiana. Su visión era demasiado unanimista como para comprender las fracturas y los reproches constantes entre dirigentes de casi todas las extracciones. El partido Demócrata Cristiano, que despertó sus expectativas, era escenario de las mismas disputas. Los sectores que veían con simpatía su programa no desconocían las limitaciones de una agrupación tan imbricada ideológicamente. Según José Luis de Imaz, los miembros de su generación eran incapaces de convertirse en "hombres de partido",

Nos gustaba que nos llamaran, satisfacía nuestro 'ego' que prestaran correcta atención a nuestro curriculum. Pero lo que más nos placía era que nos 'cooptaran'. Desde el poder militar se nos liberaba de los costos de la lucha por el poder. Presentábamos el activo - nuestra impoluta vida profesional - y nos eximíamos del pasivo: la pelea cotidiana dentro de un partido político en el que no sólo no se respetarían nuestros títulos, sino que incluso se nos pospondría a causa de ellos (IMAZ, 1977: 249). 
La relación entre los intelectuales católicos y la cúpula de la Iglesia también entró en crisis. Quienes abogaban por las nuevas ideas se distanciaron críticamente de una jerarquía a la que consideraron timorata y acomodaticia, incapaz de comprender los cambios que se producian en la teología del Concilio Vaticano. Durante la organización del golpe de 1955, los humanistas cristianos evitaron mezclarse demasiado con los hombres de la vieja guardia, a pesar de que las circunstancias reclamaran un frente unido para oponerse al peronismo. ${ }^{5}$ Después de 1955 , cuando esas diferencias se hicieron cada vez más públicas, la jerarquía buscó recomponer la disciplina interna, haciendo llamados "a la unidad de los católicos", que no tuvieron mucha repercusión. Por más que la jerarquía convocara a los creyentes a ser fieles a su identidad, los fraccionamientos del mundo cultural y político del catolicismo eran lo suficientemente profundos como para obviarlos. Roberto Bonamino, que había sido codirector de El Pueblo en sus años más nacionalistas, luego del derrocamiento de Perón pensaba que la unificación política de los católicos, como ideal "tal vez requiera el sacrificio de hombres, pero, en cristiano no son los hombres los que deben prevalecer por encima de las conveniencias comunes". (BONAMINO, 1955: 18-19). Los jóvenes maritanianos de la revista Comunidad rechazaron constantemente el convite. Desde su perspectiva, la división política de los cristianos no era un escándalo - como denunciaban muchos clérigos - porque la diversidad de posiciones no sacrificaba la unidad en Cristo. (COMUNIDAD, 1956).

La conflictividad en el seno del pensamiento católico en 1955 era similar a la que se producía en el resto de la intelectualidad argentina. Sin embargo, en el medio de los debates que se insinuaban, la llegada de un nuevo Papa al trono de Pedro en 1958 se convertiría en un vehículo de esperanza para los intelectuales católicos de la generación del cincuenta.

\footnotetext{
${ }^{5}$ José Luis de Imaz ha señalado que la primera dirigencia de la Democracia Cristiana quería "hacerles purgar" a él y a otros jóvenes nacionalistas su pasado peronista (IMAZ, 1977). Mario Amadeo, por su parte, señaló que en una reunión previa al golpe de estado de 1955 en la que estuvieron presentes Ayarragaray, Dell'Oro Maini, Oscar Puiggrós y otros dirigentes demócrata cristianos, le "manifestaron categóricamente que ellos venían trabajando en un movimiento que contaba ya con muchos años de elaboración, que ese movimiento tenía líneas definidas y una elevada tradición en el pensamiento y la política y que no era posible diluirlo en una estructura que abarcara núcleos de muy diferente origen doctrinario". "Mucho me temo" señalaba "que nuestros hermanos en la fe hayan aceptado sin muy riguroso beneficio de inventario las acusaciones que sectores de izquierda lanzaron contra los católicos de origen nacionalista con ánimo de dividirnos y que - acaso sin proponérselo - hayan hecho el juego al enemigo declarado de nuestros comunes ideales" (AMADEO, 1956: 44).
} 


\section{El Concilio Vaticano II en Argentina}

Las divisiones dentro del campo de los intelectuales católicos revelan una profunda complejidad y evolución. Con ello, queda claro que la división entre "progresistas" y "reaccionarios", o, "concililiares", "posconciliares" y "preconciliares", debe estar sujeta a constantes verificaciones. En la misma línea, más que un tema que nos permita identificar el eje central de las disputas en torno al Concilio Vaticano II, pensar al Concilio como un evento permite corroboran que éste en parte continuó y en parte interrumpió el amplio debate teológico y eclesial que se inició a partir de la Segunda Guerra mundial. Específicamente, y dejando de lado toda pretensión totalizante, el Concilio representó en el campo de las ideas del catolicismo argentino una ampliación de la superficie discursiva, operando una crisis de legitimidad (LATOURELLE, 1990; ALBERIGO, 1999; GREELEY, 2004; HORN, 2009; MCLEOD, 2010; GRAZIANO, 2012; HORN, 2015).

La crisis de la cristiandad debe ser entendida como un proceso de crisis de legitimidad de los pilares de autoridad asentados en el catolicismo pre-conciliar. Al ampliar el espacio de acción de los laicos, la pluralización de las estructuras eclesiales legitimaron la creación de una opinión pública en su interior. ${ }^{6} \mathrm{La}$ existencia de este espacio permitió que los discursos críticos y reformistas, especialmente aquellos que elaboraban los teólogos europeos, tuvieran un ámbito para su difusión y no pudieran ser simplemente eliminados. ${ }^{7}$ El Concilio produjo una distensión en el plano de las obligaciones sociales generadas por la identidad religiosa. Esta afirmación puede verificarse en la pérdida del temor, por parte de los pensadores católicos, de expresar a viva voz sus diferencias, hacerlas públicas e incluso utilizarlas como parte de una estrategia auto-legitimadora. Aunque las controversias dentro del catolicismo tenían una

\footnotetext{
${ }^{6}$ Daniel Levine ha señalado que el Concilio Vaticano II hizo pública una discusión sobre dos modelos eclesiales: el primero, entendía a la Iglesia como una institución jerárquica, el segundo, la identificaba como una reunión del pueblo de Dios. Analizando el caso de las iglesias colombianas y venezolanas, Levine sostiene que el Concilio proveyó a la Iglesia nuevos modelos de relación con la sociedad, ligados a 1) un fuerte activismo social 2) la toma de decisiones colegiada y 3), una creciente participación de los laicos en la vida de la Iglesia. Levine señala a su vez que, tanto en Colombia como en Venezuela, las organizaciones creadas para "reconquistar el mundo" basándose en el modelo de la recristianización, irónicamente se convirtieron en "sospechosas" para la jerarquía, por la relación que entablaron con el mundo moderno y los discursos que arrastraron al seno de la Iglesia (LEVINE, 1978: 517-544).

${ }^{7}$ Gerard Defois, sostiene que la crisis que abre el Concilio implica la perdida del referente "normal" de la estructura simbólica del catolicismo. No significa sólo la mutación de valores y representaciones sino que al repensar la relación entre Iglesia y mundo, se abrió en el seno del catolicismo una tensión entre los valores "institucionalmente legítimos y los valores socialmente legítimos" (DEFOIS, LANGLOIS \& HOLSTEIN, 1973: 51).
} 
larga historia, lo novedoso en torno al Concilio fue que la diversidad como fenómeno ganó un lugar legitimo dentro del pensamiento católico. ${ }^{8}$

Pío XII, alarmado en 1950 por la difusión de ideas que en Roma se caratulaban como "neomodernistas", emitió la encíclica Humani Generis. Como sostenía un viejo contrincante de Maritain, el Papa intentó "hacer frente a esta peligrosa penetración del pensamiento específicamente moderno dentro de la filosofía y de la teología cristiana" (MEINVIELLE, 1966:246). La encíclica condenaba tres niveles de errores 1) admitir "sin discreción ni prudencia el sistema evolucionístico" 2) el idealismo, el inmanentismo el pragmatismo y el existencialismo. 3) el historicismo. Entre otras condenas, afirmaba que

Lo que algunos pretenden es disminuir lo más posible el significado de los dogmas; y librarlos de la manera de hablar tradicional [...] a fin de volver, en la exposición de la doctrina católica, a las expresiones empleadas por la Sagrada Escritura y por los Santos Padres [...] según ellos, los misterios de la fe nunca se pueden significar con conceptos completamente verdaderos, mas sólo con conceptos aproximativos y que continuamente cambian [...] De lo dicho es evidente que estos conatos, no sólo llevan al relativismo dogmático, sino ya de hecho lo contienen; pues el desprecio de la doctrina tradicional y de su terminología favorece ese relativismo y lo fomenta (CRITERIO, 1950: $601)$.

La encíclica condenaba en forma abierta los intentos de renovación y tenía como destinatario directo al jesuita y científico Pierre Teilhard de Chardin; sin embargo se vieron desautorizados todos aquellos que habían expresado su intención de transformar de una u otra manera las bases en la que sustentaba el modelo de la cristiandad.

Algunos impulsores del debate conciliar, como Mauriac, Leclercq y Guitton, eran viejos conocidos en el medio argentino. Otros rápidamente se convirtieron en las caras visibles de la renovación. El nombre del padre Yves Congar se volvió pan del día a partir

\footnotetext{
${ }^{8}$ Es interesante en este sentido la opinión de un intelectual católico como Jorge Mejía. En 1966 afirmaba que "La creación de una opinión pública en la Iglesia supone, en efecto, una operación delicada y vigorosa [...] Porque la opinión pública en la Iglesia o sencillamente no existe, o cuando existe tiene todavía características de brote lleno de promesas [...] Reconozcamos, sin embargo, que, según el estilo de los tiempos y con rasgos todavía indistintos, el 'público' en la Iglesia nunca ha dejado de expresar su opinión [...] En nuestro sentido, crear una opinión pública en la Iglesia es despertar la conciencia de la comunidad eclesial a la colaboración en una obra común [...] dejemos que se disienta de nuestra opinión, alegrémonos por ello, procuremos aprender de quien disiente. Y cuando nosotros disentimos, hagámoslo con la conciencia de que no por eso poseemos la llave de la ciencia ni con nosotros solos está casada la ortodoxia" (MEJÍA, 1966: 446).
} 
de los años sesenta. Congar había protagonizado, junto al mítico grupo de Lyon en los años treinta, el desarrollo de la nouvelle théologie. Su libro, Los cristianos desunidos de 1937 fue considerado "peligroso" por Roma. Tuvo problemas para circular y fue prohibida su reimpresión. La escuela Le Saulchoir, en la que Congar participaba, se dispersó, y las reiteradas condenas de Pío XII a las innovaciones teológicas lo mantuvieron en un discreto y oscuro lugar (JOSSUA, 1966). En Argentina sus artículos se reproducían con asiduidad en Criterio, pero la nouvelle théologie era cuestionada desde la Revista de Teología de la Plata, dirigida por monseñor Rau. Ernesto Segura - uno de los representantes del episcopado argentino durante el Concilio - señalaba en 1954 que esta "novedad" engendrada alrededor de la revista La vie spirituelle, exponía una "desconfianza creciente hacia los medios externos, hacia los reglamentos, hacia las reuniones de misa, hacia la Acción Católica". Segura afirmaba que el menosprecio por lo institucional, por los medios "humanos", llevaba al menosprecio hacia la Iglesia y la jerarquía, es decir, llevaba directamente a la rebelión.

La atención a partir del Concilio se concentró en el problema de la inseción del catolicismo en la ciudad secular. Este tópico se convirtió en el manto que cubrió todo el período conciliar y post-conciliar, con consecuencias y derivaciones múltiples. Las transformaciones en torno a la relación con lo mundano implicaban para el catolicismo, en primer lugar, el fin del modelo de aislamiento y recristianización, que fue defendido hasta su último aliento por Pío XII. Quienes sostenían el modelo de la cristiandad pasaron a ser los "marginales" intelectuales en Argentina, sostenidos casi exclusivamente por la jerarquía eclesiástica. Ésta se servía de cualquier discurso que anatematizara con cierta altura las ideas en boga en la Europa conciliar.

El Concilio le había otorgado un lugar especial a los laicos y se discutía su cambio de situación en el seno de la Iglesia. La construcción de un conjunto de instituciones para recristianizar la sociedad a partir de los años veinte, se volvía ahora una verdadera "opinión pública", dispuesta a ejercer la critica a sus pastores. En 1962, al iniciarse las sesiones en Roma, Criterio abrió sus páginas para que distintos representantes del catolicismo expresaran sus expectativas sobre el Concilio. José Mirabella - que se definía como un "militante laico“- sostenía que

...el concilio debe tratar de integrar a la Iglesia en el mundo moderno, bregar contra la tendencia a secesionarse, que es una nota fundamental de la época [...] Es principal que haga que los hombres de Iglesia y los católicos en 
general abandonen el espíritu de intransigencia, de autoritarismo, de autosuficiencia, ese orgullo consciente o inconsciente que lleva a ver en otros las causas de los males de la humanidad, sin darse cuenta de la proporción que nos cabe a nosotros en su origen" [...] "Se debe hacer del laicado, un conjunto de personas, que sienten, piensan y obran, no un rebaño sin voz al que se conduce ciegamente a su salvación...”. (SEGURA, 1954: 69).

El período abierto por el Concilio Vaticano II se caracterizó por la ampliación de la superficie discursiva del campo católico. De lo precedente se deriva la necesaria aparición de nuevas claves interpretativas, que inmediatamente se integraron a la competencia por la legitimidad, en un campo mucho más horizontal que el del período anterior. No dejó de existir un centro jerárquico que emitía discursos de una fuerza ineludible; cuya autorización y desautorización careciera de importancia. Sin embargo, ese poder legitimador se había reducido - al mismo tiempo que otras fuentes de legitimidad se hicieron visibles - en tanto los católicos asumieron que estaban en "estado de concilio", es decir, habilitados formalmente a repensar y criticar, hacia adentro y hacia fuera, a la Iglesia y al mundo donde se insertaba. Enrique Dussel lo afirmaba sin tapujos en 1964

... el Concilio Vaticano II ha autorizado a un cierto sector del catolicismo latinoamericano que antes debía guardar silencio. Este sector podrá ahora pensar teológica y pastoralmente el modo de vivir el cristianismo dentro de la civilización técnica universal que se instala lentamente en América Latina y que se le denomina a veces: el Mundo Moderno (DUSSEL, 1964: 501).

Estas nuevas claves interpretativas, discursos que cuestionaban el status quo, revelaban la fuerte discontinuidad que produjo el Concilio en la configuración del campo intelectual católico. Éstas variaban desde una franca oposición al tomismo, hasta una adhesión más o menos crítica a la Teología de la Liberación. Más que un cambio en términos de contenido, lo que se produce en los años sesenta es un nuevo tipo de relación en el campo católico, basado en pautas modernas. Algunos autores han negado las dimensiones de esta transformación. Muchos han reducido la discusión a un enfrentamiento entre integrismos "de izquierda" y de "derecha". ${ }^{9}$ Se ha querido ver en

\footnotetext{
${ }^{9}$ Por ejemplo, José M. Ghío sostiene que "In fact, the very modernity with which the Council was beginning to establish a relationship was made liable for the oppression suffered by the peoples at the periphery of
} 
aspectos comunes del catolicismo la semilla de un mismo mesianismo. Esta operación implica obviar la riqueza y complejidad de los debates en cuestión. Desde esta óptica, sólo la matriz de la modernidad, entendida en términos del liberalismo, serviría para dividir a los "verdaderos" de los "falsos" renovadores. Esta perspectiva niega la particular forma de apertura que los católicos que apoyaron el Concilio adoptaron en relación a "lo mundano".

Los debates conciliares tuvieron distinta recepción en Argentina. Algunas publicaciones católicas como la revista Estudios dedicaron poco espacio a la difusión de lo que sucedía en Roma. Otras, de carácter estrictamente teológico, se ocuparon con detenimiento de los documentos conciliares, pero sin reseñar la coyuntura. Sin duda, Jorge Mejía desde las "Crónicas conciliares" en la revista Criterio representó la percepción de los cambios conciliares "día a día" y su traducción al "hombre común". Mejía representaba las ideas del humanismo cristiano que, más allá de los matices que señalábamos más arriba, ganó presencia en el pensamiento católico a partir de la postguerra. Si el eje de ese programa giraba en torno a un dialogo posible y necesario que la Iglesia (y ya no grupos aislados de laicos) debía establecer con el mundo moderno, el carisma del "Papa Juan" parecía alimentar esas esperanzas. Desde las primeras "Crónicas conciliares", Mejía afirmaba: "Es seguro que el mundo espera algo del Concilio, aunque no sepa bien qué, ni cómo" [ '...] "debe tenerse muy en cuenta la adaptación al hombre y al pensamiento moderno, con gran paciencia, si es preciso" (MEJÍA, 1962: 774).

La transición de un modelo cerrado y monolítico hacia una estructura de Iglesia abierta, como la denominaba Aranguren, implicaba la convivencia de claves interpretativas muy diversas (Aranguren, 1969). Este proceso se asentaba en una

capitalism. The situation, which in Argentina acquired a vertiginous tone as violence gradually displaced politics, suffocated the ecclesiastical renovation, and confronted it with a dichotomy between two forms of integralism: a classical one, right-wing and conservative, and another one, left-wing and revolutionary, equally subsumed under politics." (GHÍO, 1995: 299). David Rock ha señalado un tesis similar, basándose en el común rechazo del nacionalismo católico de derecha y los grupos posconciliares al liberalismo (ROCK, 1993). En la misma tesitura, Di Stefano y Zanatta han señalado "No casualmente, muchas ideas profesadas por sacerdotes y laicos en los distintos organismos que dirigían - desde la JUC, la JEC, del MSTM, al MICAR entre otras - se hacían eco de las que habían animado, en los años treinta y cuarenta, la cruzada católica por el 'nuevo orden cristiano', si bien filtrado a través de la renovación conciliar y adaptadas al clima intelectual de los años sesenta y setenta, tan impregnados de utopías socialistas como el de treinta años antes lo había estado de utopías corporativistas" (DI STEFANO y ZANATTA, 2000: 525-526). De ninguna manera negamos el substrato fáctico de estas aseveraciones; consideramos, sin embargo, que se han formulado siguiendo una caracterización del catolicismo preocupada por verificar qué elementos tiene y qué elementos le faltan en relación al liberalismo político, más que por comprender al catolicismo en sus propios términos. Al mismo tiempo, se le ha dado mayor peso a ciertos sectores del catolicismo que cristalizaron en organizaciones más o menos próximas a los movimientos armados de la década de 1970, y se ha escapado el proceso de búsqueda, las críticas a la Cristiandad como modelo, y el pluralismo propio del período conciliar. 
inestabilidad estructural. La competencia de discursos y la apertura hacia la crítica, producían en el campo católico el veloz envejecimiento de aquellas posturas que, promoviendo el cambio, se emitieron antes de 1962. De esta manera, Enrique Dussel en 1970 pensaba ya que Congar "... sigue con una conceptualización de cristiandad" que "no es realmente la que se necesita" (DUSSEL, 1971: 330). Algo parecido se evidenció en la recepción que tuvo en los medios católicos argentinos el libro de Maritain, Le paysaine de la Garonne, donde en un tono autobiográfico demostraba sus temores y diferencias con el rumbo que había tomado la teología durante el Concilio (COMUNIDAD NACIONAL, 1967: 15). Las críticas revelaban las transformaciones vertiginosas de una dinámica que había adoptado el campo intelectual, en la cual "los maestros" duraban muy poco. Una nota sobre el libro en Criterio, del franciscano Silvio de Schrijver, reseñaba amargamente sus ideas. Para Maritain ya no había ni filosofos ni teologos de talla. Su opinión de Teilhard de Chardin era demoledora y "rozaba lo grotesco". Su mirada sobre el mundo moderno contrariaba las conclusiones del Concilio. "Mientras la Iglesia nos invita a bautizar el mundo y a sacralizar todo lo que puede ser bautizado y sacralizado," sostenía Schrijver

...y nos afirma que ese todo es todo, menos el pecado; Maritain nos invita en nombre de una interpretación personal del Concilio, a abominar de todo esto [...] se aleja del mundo real y nos invita a volver al pequeño cenáculo cerrado al mundo y reservado tan solo a una "elite", inspirada en el tomismo maritainista (SCHRIJVER, 1967: 432).

La crítica a la cristiandad se hizo consciente y explícita. Los intelectuales católicos experimentaron la sensación de estar frente al fin de una época. En esa clave, Enrique Dussel dividía la historia de la Iglesia en tres etapas: la iglesia primitiva, basado en una gran libertad litúrgica y la existencia de pequeñas comunidades de base donde "El hombre conocía al hombre y podía compartir sus sufrimientos y sus alegrías" (DUSSEL, 1971: 289); la cristiandad, y el período posterior, que se iniciaba a partir de la convocatoria y desarrollo del Concilio Vaticano II. Tal periodización se combinaba con la reivindicación de la Iglesia original y primitiva, por su sencillez y sentido de la comunidad. Junto con el modelo de la cristiandad, entendido como un sistema de universalización de la tradición católica latina, debía ser eliminado el pensamiento 
europeizante que lo acompañaba. Dussel proponía entonces "pensar como argentinos", o mejor, como latinoamericanos (DUSSEL, 1964: 484).

El Concilio despertó la conciencia de los católicos sobre la realidad crítica que los circundaba. Narrar la historia de la Iglesia desde una perspectiva latinoamericana se convirtió en una opción indiscutible y en una señal identitaria para los intelectuales cristianos del período posconciliar. Justino O'Farrell reseñaba el proceso inexorable que nos llevaría a perder nuestras últimas aspiraciones de europeos. "Entre los rasgos principales del desenvolvimiento argentino es posible discernir los que preanuncian la rápida latinomericanización de lo que era la antigua Argentina Europea" (O'FARRELL, 1966:121). A la identidad latinoamericana se amoldaba perfectamente la Teología de la Liberación, que en términos de Dussel, representaba un verdadero corte con el modelo de la cristiandad, el abandono de la noción de totalidad y del pensar en términos europeos (BEOZZO, 1992).

El Concilio generó la apertura a corrientes que replantearon muchos de los principios que hasta ese momento habían sido considerados inamovibles en la Iglesia. Pero al mismo tiempo, obligó a salir a la palestra a quienes desde la muerte de Pío XII veían en los movimientos del tipo nouvelle théologie la penetración del mismísimo anticristo en el seno de la Iglesia. Entre ellos, Julio Meinvielle aparecía como uno de los intelectuales católicos que el clima democratizador de la postguerra no había logrado doblegar. Nacionalista y antisemita, representaba un núcleo de pensamiento que era apañado por la jerarquía eclesiástica, como lo demuestran las licencias concedidas a sus libros. La cúpula de la Iglesia tal vez no compartiera absolutamente todas sus ideas, - tan políticamente incorrectas en 1965 -, pero a partir del Concilio los unía la común sensación de estar asediados, sin poder respaldarse cómodamente en la autoridad romana. Como hacía treinta años lo había hecho con Maritain, a mediados de los sesenta Meinvielle encaró la tarea de refutar a los que consideraba sus herederos intelectuales.

Meinvielle y sus contrincantes no discutían exactamente los mismos temas. Ellos se preguntaban cómo los católicos podrían seguir viviendo su cristianismo en el mundo moderno. Eso explicaba su optimismo, en tanto redescubrieron una sociedad mucho menos corrupta y laicista de lo que se presentía hasta ese momento. Para Meinvielle el problema se limitaba a organizar una sociedad basada en los principios católicos, colocando al poder al servicio de la función evangelizadora de la Iglesia. Allí el optimismo trocaba en pesimismo, y el hombre moderno se presenta como el símbolo del 
alejamiento de las enseñanzas de la Iglesia, en tanto ésta había perdido peso y funciones desde la emergencia de la modernidad.

Meinvielle rechazaba la idea de que se estuviera produciendo un proceso hacia una "secularización de la Iglesia" convergente con una "eclesialización del mundo", como sostenían los "teólogos progresistas".

El 'fuera de la Iglesia no hay salvación', por mucho que se explique en un sentido muy mitigado, como si la humanidad caminara 'invisiblemente' 'anónimamente', 'de incógnito' hacia la Iglesia, sólo podía hacerlo si caminase, al menos, hacia un Dios personal y providente; pero si, en su vida pública, esta humanidad no levanta otras realidades que lo Económico, o la Cultura, o el Sexo, o la Libertad, mal se podrá decir que camina hacia Dios cuando es impulsada por realidades puramente terrestres (MEINVIELLE, 1966: 116).

El esquema mental de Meinvielle no dejaba escapar ningún concepto a las disputas entre categorías opuestas, binarias e irreconciliables: Dios o Satán, Iglesia o mundo, trascendente o histórico. Las relaciones entre el Estado y la Iglesia, como representantes de lo humano y lo divino, tampoco podían ser leídas fuera de una relación de subordinación. "...Congar omite" continuaba Meinvielle

...la valoración de un elemento capital, cual es la de fijar que 'la vida pública' del mundo o de la humanidad se ponga al servicio del fin de la Iglesia. Al no servir al fin de la Iglesia, esta 'vida pública', que hoy se confunde con 'un poder público que actúa en todo el mundo y sobre todo el hombre', ha de actuar en la erección de la Ciudad de Satán (MEINVIELLE, 1966: 107).

La última postura reseñada llevaba implícita la defensa del sistema en el cual la Iglesia se imponía al mundo, y sus leyes y las del Estado se confundían. Para Meinvielle, la cristiandad no era un período de la historia humana, sino un modelo de comportamiento a seguir por el poder y los hombres frente a la Verdad.

$\mathrm{Al}$ resistirse con tanta fuerza a la Cristiandad - a la que llaman odiosamente 'Teocracia' -, por la misma fuerza de las cosas, se someten a otra 'Teocracia', a la Teocracia de Satán...[...] EL planteo de Congar, O. P., tal como aparece 
formulado, lleva implícito la negación del carácter mismo de toda existencia cristiana (MEINVIELLE, 1966: 110).

En la entretela del discurso de Meinvielle se dejaba ver una imagen de Dios que se contraponía a las nuevas representaciones de la trascendencia. Como señaláramos al principio, la teología que precede y rodea al Concilio había construido una noción de Dios más consensual, una filosofía en la cual los hombres prestaban su aceptación a la palabra de Cristo. El Dios de Meinvielle, en cambio, era el Dios autoritario de la Cristiandad, al que los hombres deberían temer y respetar, más que conocer y amar. "Es necesario señalar que Cristo, que salva" aclara Meinvielle, "también pierde. Es una piedra de tropiezo, de separación. [...] Cristo une, pero también separa. En Mateo dice Cristo 'No penséis que he venido a poner la paz, sino espada" (MEINVIELLE, 1966:94). Meinvielle representaba las resistencias de un sector del catolicismo a la presencia de nuevas claves interpretativas en el campo intelectual católico. Pero no deberíamos ilusionarnos con la imagen absoluta y nítida de un personaje como "el padre Julio". La situación de los católicos frente a las innovaciones fue más sinuosa, menos rígida, más compleja y llena de matices.

En Octubre de 1964, en una larga argumentación, Jorge Mejía bregaba por la aprobación del "Esquema XIII" (luego la constitución Gaudium et Spes) conteniendo la declaración sobre la libertad religiosa. "El mundo no se está construyendo sin nosotros, sino contra nosotros; mucho tiempo hemos vivido en una ciudadela amurallada, corresponde ahora, no bajar los puentes, sino derribar los muros"(MEJÍA, 1964: 816). Cuando el Concilio llegaba a su final, Mejía ensayaba el balance de una década. "La teología de los documentos conciliares es [...] la teología de la periferia. Los grandes artífices de esos documentos han sido hombres que, hasta hace poco, eran sospechosos en Roma" (MEJÍA,1965: 957). En la última sesión el documento sobre la libertad religiosa fue finalmente aprobado. Mejía se sentía satisfecho porque la obra del Concilio, el programa que el humanismo cristiano había impulsado desde el fin de la segunda guerra, ahora era dogma en la Iglesia: "El Concilio, dice el Papa, no ha pronunciado anatemas, sino reconocido sus necesidades y valores, y procurado presentar un nuevo humanismo"(MEJÍA, 1965: 958).

El Concilio llegó a su fin en 1965 y el círculo se cerró sobre sí mismo. De la Humani Generis a la Gaudium et Spes, habían pasado quince años y tres Papas. El Concilio representó la explosión de un clima asfixiante, de una situación, para muchos, 
insostenible. Quedaba por adelante la dura tarea de adaptación y puesta en práctica de las disposiciones conciliares. Sin duda el Concilio vino ha sancionar una línea que en su propia lógica, abriría un conflicto que por muchas décadas laceraría el campo católico. Hacia los años setenta, este clima de apertura pareció cerrarse. Desde mediados del papado de Paulo VI y con mucha mas claridad con el reinado de Juan Pablo II, se intentó que los católicos volvieran a un respeto "tradicional" por la autoridad. Sin embargo, esas medidas fueron más efectivas entre los obispos y sacerdotes - que pronto se dieron cuenta que la colegialidad discutida en el Concilio no se concretaría - que entre los intelectuales. Estos últimos no se resignaron a volver al mundo cerrado y restrictivo del reinado de Pio XII (HORN, 2015).

\section{A modo de balance}

Desde principios de los años cincuenta se afirmó en nuestro país una nueva generación de intelectuales portadora de una mirada crítica hacia el modelo de la cristiandad. Esa crítica no era homogénea: algunos asumían lo temporal al tiempo que defendían la identidad católica como una necesidad. Otros, más radicalizados, exigían que la ruptura se tradujera en un compromiso con la transformación de las estructuras económicas y sociales.

La nueva generación intentó pensar la realidad apartándose del espíritu de cruzada que había marcado a los intelectuales católicos del periodo de entreguerras. Querían llevar adelante (y no sólo declamarlo) una verdadera separación entre lo profano y lo sagrado, juzgando al mundo desde una óptica independiente. No deseaban dejar de ser católicos, ni creían que ambos niveles tuvieran la misma categoría. Su discurso seguía emitiéndose desde una posición religiosa, pero se sintieron hijos de una época que terminaba con diecisiete siglos de ostracismo mental.

Esta transformación en el pensamiento católico fue posible por la modificación de la estructura de relaciones dentro del campo. En el interior de la Iglesia surgió una esfera crítica, un ámbito donde circularon estos nuevos discursos. Como hemos analizado, éste fue el resultado de un largo proceso nacido del impulso que la jerarquía brindó a la organización de entidades como la Acción Católica, basadas en el modelo de reconquista del mundo y aislamiento del creyente. Estos espacios se convirtieron en ámbitos de discusión y permitieron que los católicos desarrollaran un proceso de 
autorreconocimiento. Esta esfera crítica quedó en evidencia en los distintos eventos que jalonaron desde principios de los cincuenta el conflicto con el peronismo, y que en 1955 se hizo inocultable.

Creemos haber demostrado la discontinuidad en el pensamiento de la generación de intelectuales integristas de los años treinta y cuarenta con la de los años cincuenta. Más allá de quienes sostienen que ninguna de las dos rompió con una concepción esencialista de la cultura, lo cierto es que la marca que distinguió a la generación del cincuenta es su distanciamiento del modelo de la cristiandad. Ese proceso no fue lineal, ni homogéneo, ni estuvo libre de condicionamientos. Alejándonos de las disyuntivas temporales, como "avanzados" y "retrógrados", comprendimos la variedad de posiciones que se desplegaron en términos espaciales alrededor de un centro temático: la cristiandad como modelo. Su crisis modificó la lógica del campo, y debido al desarrollo de una conciencia crítica, la forma de autoridad tradicional perdió efectividad.

Dejaríamos un vacio historiográfico si obviaramos la existencia de quienes desde perspectivas distintas, buscaron abrir el catolicismo al mundo en un aggiornamiento que empezó mucho antes que el Concilio le diera un estatuto formal. Instalaron y difundieron el discurso conciliar, y aspiraron a concretar una religiosidad más pura, más austera, más democrática y solidaria. El otro, ese enemigo desconocido que acechaba en las afueras de la cristiandad, se convirtió en alguien que, desde su alteridad, podía hacer de ellos mejores cristianos.

\section{Fuentes}

AMADEO Mario (1956). Ayer, hoy, mañana. Buenos Aires: Gure.

ARANGUREN, José L. (1969). La crisis del catolicismo. Madrid: Alianza.

BONAMINO, Roberto (1955). Unidad política entre los cristianos. Izquierdismo, laicismo, materialismo. Estudios, n. 471, nov./dic., pp. 18 - 19.

COMUNIDAD (1956), n. 1.

COMUNIDAD NACIONAL (1967), n. 41.

DUSSEL, Enrique (1964). Hacia una historia de la Iglesia latinoamericana. Stromata, vol. XX1. n. 1, pp. 483-505.

(1971). Crisis de la Iglesia latinoamericana y situación del pensador cristiano en Argentina. Stromata, Vol XXVIII, n. 3, pp. 277-336.

FERRARI, Gustavo (1958). Un dios cotidiano, un Dios ausente. Criterio, n. 1305, 8 de abril, pp. 250-251.

FERREIROS, Héctor (1958). Denevi - Viñas y nuestro contorno literario de hoy. Estudios, n. 493, mayo, pp. 250-252. 
FLORIA, Carlos (1955). Proyección histórica de una generación desamparada. Criterio, n. 1243,8 de septiembre, pp. 649-650.

(1958). Nuestro triángulo. Criterio, n. 1319, 13 de diciembre, pp. 810-812.

FRANCESCHI, Gustavo (1957). Austeridad. Criterio, n. 1281, 11 de abril, p. 213.

IMAZ, José Luis de (1977). Promediados los cuarenta. Buenos Aires: Sudamericana.

JOSSUA, Jean P. (1966). Yves Congar: un servidor doctrinal del pueblo de Dios. Buenos Aires: Guadalupe.

MARITAIN, Jacques (1936). Humanisme Integral. Paris: Aubier.

MEINVIELLE, Julio (1966). La Iglesia y el mundo moderno. Buenos Aires: Theoria.

MEJÍA, Jorge (1962). La inauguración del Concilio, hecho universal. Criterio, n. 1414, 25 de octubre, p. 774.

(1964). Cronica Conciliar. Criterio, n. 1463, 12 de noviembre, pp. 813-816.

(1965). Crónica Conciliar. Criterio, n. 1489/90, 24 de diciembre, pp. 957-958.

(1966). Creación de opinión pública en la Iglesia. Criterio, No 1502,23 de junio, pp. 446-450.

O'FARRELL, Justino (1966). La acción pastoral de la Iglesia en la Argentina. Su evolución. Teología, n. 9, pp. 115-143.

PÉREZ CATÁN, Mauricio (1956). Un totalitarismo que no cuenta para ciertos intelectuales argentinos. Estudios, n. 479, octubre, pp. 21-25.

PIO XII. Encíclica Humani Generis (1950). Criterio, n. 1123, 14 de septiembre, p. 601.

SCHRIJVER, A. Silvio de (1967). Jacques Maritain y "Le paysan de la Garonne". Criterio, n. 1526, 22 de junio, pp. 431-432.

SEGURA, Ernesto (1954). ¿Cristianismo de trascendencia o cristianismo de encarnación?. Revista de Teología, n. 14, p. 69.

WAST, Hugo (1958). El triste destino del intelectual católico. Estudios, n. 500, diciembre, pp. 763-766.

\section{Referencias Bibliográficas}

ALBERIGO, Giuseppe (1999). Historia del Concilio Vaticano II. Leuven; Salamanca: Peeters: Sígueme.

BEOZZO, José O. (1992). Cristianismo e Iglesias en América Latina en vísperas del Vaticano II. San José: Editorial DEI.

DEFOIS, Gérard ; LANGLOIS, Claude \& HOLSTEIN, Henri. (1973). Le Pouvoir dans L'Église. Paris: Editions du CERF.

DI STEFANO, Roberto \& ZANATTA, Loris (2000). Historia de la iglesia argentina: desde la Conquista hasta fines del siglo XX. Buenos Aires: Grijalbo Mondadori.

GHÍO, José M. (1995). Catholic Church and Politics in Argentina (1880 - 1989). Ph.D.. Columbia University, New York.

GHÍO, José M. En Argentina faltó una iglesia liberal. Todo es Historia, n. 286, p. 71.

GRAZIANO, Manlio (2012). El siglo católico: la estrategia geopolítica de la Iglesia. Barcelona: RBA.

GREELEY, Andrew M. (2004). The Catholic Revolution New Wine, Old Wineskins, and the Second Vatican Council. Berkeley y Los Angeles: University of California Press.

HORN, Gerd-Rainer (2009). The Spirit of '68: Rebellion in Western Europe and North America, 1956-1976. Oxford: Oxford University Press. 
(2015). The Spirit of Vatican II: Western European Progressive Catholicism in the Long Sixties. Oxford: Oxford University Press.

LATOURELLE, René (1990). Vaticano II: balance y perspectivas: veinticinco años después (1962-1987). Salamanca, Sígueme.

LEVINE, Daniel (1978). Authority in Church and Society: Latin American Models. Comparative Studies in Society and History, vol. 20, n. 4, oct., pp. 517-544.

McLEOD, Hugh (2010). The religious crisis of the 1960s. Oxford; New York: Oxford University Press.

ROCK, David (1993). La Argentina autoritaria: los nacionalistas, su historia y su influencia en la vida pública, Buenos Aires: Ariel.

SARLO, Beatriz (2001). La batalla de las ideas. Buenos Aires: Ariel.

Artigo recebido em 30 de novembro de 2018.

Aprovado em 11 de dezembro de 2018.

DOI:10.12957/intellectus.2018.39086 